\title{
CALEI- DOSCOPIO \\ Búsquedas de sentido desde los horizontes de la hermenéutica
}

Luján Salazar, Enrique (comp.), De la analogía al simbolo. Vertientes de la Hermenéutica, UAA, Aguascalientes, 2007, $168 p p$.

Q uisiera antes que nada, agradecer la invitación por parte de Enrique Luján Salazar, para presentar un libro que ha escrito, junto con otros investigadores, que se titula De la analogía al símbolo. Vertientes de la Hermenéutica. El prólogo del libro está escrito por uno de los más prestigiosos filósofos mexicanos: Mauricio Beuchot, quien ofrece de manera esclarecedora el hilo conductor de un libro que profundiza en diversos campos del saber y del conocimiento con base en el método hermenéutico que denomina analógico. Según las palabras del mismo Beuchot, la hermenéutica analógica se sitúa entre la univocidad y la equivocidad. La interpretación unívoca nos permite dar un significado preciso a una palabra, de tal manera que en cualquier contexto en que parece esa palabra siempre significa lo mismo. En cambio, la interpretación equívoca es aquella que no nos permite determinar el significado preciso de una palabra, pues en cada contexto significa algo diferente. En general, la ciencia tiende a promover interpretaciones unívocas del mundo, mientras que el arte y la literatura por el contrario, interpretaciones equívocas. La analogía que propone Beuchot como espacio intermedio entre los símbolos unívocos y lo símbolos equívocos, permite superar, por una parte, los excesos de una interpretación dogmática de los símbolos que destruye toda equivocidad y, por otra parte, las 
derivas subjetivistas e historicistas que conducen a un relativismo insuperable. La hermenéutica analógica tiene como finalidad, entre otras, romper con las fronteras rígidas entre el ámbito del saber científico con un fuerte carácter objetivo y el ámbito de la creación poética y literaria con un carácter más subjetivo y emotivo, permitiendo un diálogo o comunidad de significados (sin caer en el relativismo y el historicismo) entre la univocidad (inalcanzable) de las teorías científicas y la equivocidad (insuperable) de los símbolos históricos, artísticos y literarios.

Según nuestro pensador, la hermenéutica analógica no implica una superación de la equivocidad del lenguaje dando lugar a un lenguaje perfectamente claro y transparente. Es decir, totalmente idéntico a si mismo y exento de contradicciones como las ideas claras y distintas de Descartes. Pero por otra parte, tampoco se rinde ante la equivocidad insuperable del lenguaje humano que desemboca en una interpretación infinita que destruye el sentido que se esconde en el texto, convirtiendo la interpretación en una tarea infinita sin finalidad alguna, como un barco a la deriva que anuncia el nihilismo y la crisis de la cultura. Según Beuchot, la interpretación equívoca tiene la virtud de permitirnos escapar de la interpretación unívoca, sin embargo, puede implicar el riesgo del relativismo.

La hermenéutica analógica, por tanto, se enfrenta principalmente con el problema de la equivocidad del lenguaje, y por tanto, con el problema del relativismo que se sigue de esta hermenéutica que se basa en esta equivocidad del lenguaje. En otras palabras, esta propuesta se tiene que enfrentar fundamentalmente con el carácter ambiguo y equívoco del lenguaje, y su gran apuesta consiste en superar la equivocidad del lenguaje sin incurrir en la univocidad del lenguaje. La hermenéutica analógica que propone Beuchot, y que tratan de aplicar los autores del libro que estoy comentando, hace más hincapié en el principio de diferencia que en el principio de identidad. Y sin embargo, no se queda en la simple diferencia en cuanto tal, sino en la identidad en la diferencia. En otras palabras, la hermenéutica analógica nos permite interpretar los símbolos y los lenguajes que aparecen en diferentes regiones del saber y del conocimiento, tratando de dilucidar sus puntos de contacto sin 
reducir sus diferencias al lenguaje unívoco de la ciencia. En otras palabras, cada campo del saber habla de cosas diferentes, pero podemos descubrir que todas ellas nos hablan a través de símbolos análogos que nos permiten pasar de un campo a otro, sin presuponer que haya un campo del conocimiento privilegiado que dé cuenta de todos los saberes especializados. Tal era el papel que desempeñaba la filosofía o la metafísica, como la ciencia de todas las ciencias, que desde Aristóteles hasta Descartes, constituía la ciencia de los primeros principios y la reina de todas la ciencias.

La gran propuesta de la hermenéutica analógica consiste en tratar de salvar únicamente aquellos aspectos de la hermenéutica unívoca que nos impidan caer en la deriva subjetivista y relativista de la hermenéutica equívoca. Esta es la función que cumple la analogía en el campo de la interpretación: impedir al mismo tiempo la univocidad dogmática y la equivocidad relativista, y hacer posible una interpretación analógica de los símbolos.

Enrique Luján expresa de una manera muy clara las pretensiones fundamentales de una hermenéutica analógica: "A partir de una recuperación original de los diferentes sentidos de la analogía, esta hermenéutica trata de mantener la conciencia de la diversidad de significado y la historicidad que pueden tener las interpretaciones de un texto, pern sin renunciar a cierta permanencia y unitormidad de los resultados. De esta manera se puede evitar que la hermenéutica tienda sin más hacia lo equívoco y que pueda pugnar teórica y metodológicamente por alcanzar algo de univocidad. Se trata de sujetar o limitar el sentido y de tensionarlo entre su pluralidad o infinitud posible así como la pretensión de dominar en su totalidad el significado de un texto. La hermenéutica analógica reconoce la equivocidad que puede tener la interpretación de un texto pero postula la posibilidad de acotarla mediante la analogicidad".' En otras palabras, Enrique Luján considera que el fin de toda interpretación analógica es alcanzar una inalcanzable uni-

Luján Salazar, Enrique (comp.), De la analogía al símbolo, Universidad Autónoma de Aguascalientes, Aguascalientes, 2007, p. 62. 
vocidad mediante la superación de una insuperable equivocidad que se trata de conseguir a través de la analogía y la hermenéutica analógica. La analogía busca, por tanto, aproximarse a la univocidad de los símbolos partiendo de la equivocidad de los mismos, y sin embargo, su gran reto es superar la equivocidad para alcanzar la totalidad del significado de un texto, desde una interpretación no cerrada ni definitiva, como presupone la univocidad, sino abierta e inconclusa como presupone la hermenéutica analógica, es decir, no tan abierta ni imprecisa como la interpretación equívoca. La totalidad de sentido no es perfecta ni absoluta, como la interpretación univoca, pero la analogía intenta aproximarse lo más posible a esta totalidad de sentido de manera analógica, pero sin caer en la univocidad de una interpretación que pretende ser última y definitiva. Ni tan abierta e imprecisa como la equívoca, ni tan cerrada ni precisa como la unívoca, la hermenéutica analógica sería como el justo medio que nos permite conjugar la exigencia de una comprensión profunda de los textos y la contextualización histórico-social que implica toda interpretación. José de Lira Bautista, en su en- sayo titulado "Filosofía de la ciencia y hermenéutica: la idea de tradición", nos invita a pensar las teorías científicas, tan bien analizadas por Popper, Kuhn, Laudan y Gadamer, en relación con el concepto de tradición, lo cual le permite establecer un diálogo fecundo entre ciencia y hermenéutica por medio del concepto de tradición. Yolanda Padilla Rangel, en su ensayo titulado "Ciudad perdida y centro sagrado. Una interpretación simbólica de la Atlántida de Platón", desarrolla el concepto de símbolo en relación a la ciudad mítica de Platón, que renace y adquiere vida propia a través de las diversas interpretaciones, siendo muy fecunda su interpretación analógica. Caleb Olvera Romero, en su ensayo "La nada y la poesía. El entrecruce del discurso metafísico y el discurso poético", se apoya en la hermenéutica analógica para profundizar en la relación entre poesía y ontología. Marco Antonio Venegas Medrano, en su ensayo "Responsabilidad metafísica y hermenéutica del Otro", analiza las vertientes de la hermenéutica analógica a través del filósofo Emmanuel Levinas, y a través de su filosofía de la alteridad. Juan José Láriz Durón, en su ensayo "La promesa y lo trágico "con" 
el otro: un aspecto ético-moral ensayado al amparo de la hermenéutica", sigue profundizando en la relación entre la alteridad y la hermenéutica, y concretamente en el carácter ético de la hermenéutica analógica, como promesa y como comprensión del actuar humano.

Enrique Luján en su ensayo "Hermenéutica, analogía e historicidad", establece de una manera muy esclarecedora las condiciones de posibilidad de la hermenéutica analógica, distinguiendo entre una hermenéutica metodológica y una hermenéutica filosófica. La segunda es la que inaugura Gadamer, en su obra Verdad y Método, y que se distingue precisamente por separar y deslindar lo más posible la hermenéutica filosófica de cualquier método científico, y desde este punto de vista, la hermenéutica filosófica de Gadamer rompe con los supuestos de la metodología científica: "Para Gadamer- según el autor-si existe alguna conclusión práctica tendrá que ver más bien con la honestidad científica de admitir el compromiso que de hecho opera en toda comprensión y que precede a la explicación científica de los fenómenos. La intención gadameriana es filosófica, su pregunta no indaga lo que debiéramos hacer sino lo que ocurre con nosotros por encima de nuestro querer y hacer cuando realizamos la tarea de comprensión". ${ }^{2}$ Y en palabras de Gadamer. "La cuestión que nosotros planteamos intenta descubrir y hacer consciente algo que la disputa metodológica acabó ocultando y desconociendo". ${ }^{3}$ ¿Qué desvela la hermenéutica de Gadamer que nos ha ocultado la metodología científica? Nada menos que la historicidad del ser humano, es decir, el carácter histórico de toda comprensión.

Por último, quisiera hacer una reflexión sobre el concepto de símbolo, en relación con la analogía. El título del libro que estoy presentando se titula De la analogía al símbolo, vertientes de la Hermenéutica, y los autores del libro tratan de analizar el concepto de símbolo en relación con la analogía. La analogía, al igual que la metáfora y el símbolo, permite establecer relaciones de semejanza y de analogía entre diferentes lenguajes y diferentes

Op. cit., p. 53.

Lugar citado, op. cit., p. 53 
seres que ocupan lugares muy distantes entre sí, y en cierta forma, la analogía logra transformar la alteridad, y la diferencia en una experiencia cotidiana y familiar. Lo más lejano se hace familiar, y lo más extraño se convierte en una parte de nuestra experiencia más personal e íntima. La analogía permite acercar objetos que se conciben como separados por un abismo, y por tanto, la analogía lanza puentes entre tradiciones muy separadas entre sí, y permite el diálogo entre el pasado y el futuro, entre la ciudad ideal y la ciudad real. En palabras de Yolanda Padilla, un símbolo es una "...mediación indirecta y analógica que permite conjugar dos realidades, la sensible y la suprasensible". Entre estas realidades hay un límite. En el linde entre el misterio y el mundo, dice Eugenio Trías, halla el hombre el mundo de los símbolos, que le sirven para rebasar (precariamente) ese límite y para expresar, en figuras de nuestro mundo (metafóricas, metonímicas, irónicas), aquello que nos excede y desborda: el misterio. El límite de la razón se salva a través del símbolo" ${ }^{4}$ Esta

4 Ibid., p. 75. última frase, que tiene resonancias kantianas (los límites de la razón dejan un espacio para la creencia y la fe) también tiene resonancias románticas: la razón no puede explicarlo todo, y el hombre tampoco se reduce a la razón, y por tanto, el símbolo que no se deja reducir a lo racional remite al misterio del origen de la vida y de los valores último del hombre. Según Yolanda, "interpretar" consiste en "dar vida al texto" y por tanto en hacer revivir una experiencia interior a partir del contacto con el mundo y sus símbolos.

El símbolo de origen romántico se define como una aspiración al infinito, y como sostiene Robert Legros no se puede comprender la ironía romántica sin tener en cuenta esta aspiración al infinito. Sin embargo, lo infinito se hace visible a través de lo finito, lo inexpresable se manifiesta a través de lo expresable y lo inconcebible a través de lo concebible. El símbolo permite unificar los aspectos divorciados de la realidad: lo visible y lo invisible, lo real y lo ideal, lo material y lo espiritual. A través del símbolo, el hombre se disuelve en la naturaleza que le envuelve como un destino que no ha elegido, y a través del símbolo el hombre 
adquiere el poder de espiritualizar los sentidos y de sensibilizar el espíritu. El símbolo romántico en este sentido se enfrenta a la razón ilustrada que presupone la soberanía de la razón en la historia y en el destino del hombre. ¿Cómo se podría expresar la ironía romántica enfrentada con este poder de dominio y de control de la razón ilustrada? La ironía romántica nos dice que el que no sabe dónde va llega más lejos, y por tanto, vislumbra más horizontes que el hombre Ilustrado que sabe de antemano supuestamente dónde se dirige.

Robert Legros, en su obra La idea de Humanidad, contrapone dos concepciones del hombre: la ilustrada y la romántica. Y consiguientemente, contrapone de manera radical el modelo de explicación de las ciencias naturales y el modelo de comprensión de las ciencias humanas. La reducción instrumental y objetivista del lenguaje científico excluye cualquier referencia al significado del mundo y de las palabras que utilizan los sujetos para comprenderse tanto a sí mismos como el mundo en el que viven. ¿De qué nos sirve una explicación racional que nos oculta el sentido esencial de la vida? Tal es la conclusión que extrae Novalis en 1792 en su obra Los Discípulos en Sais: "El matemático propiamente dicho logrará quizás suscitar al mismo tiempo una mayor cantidad de fuerzas naturales, y poner en movimiento los fenómenos más grandiosos y los más útiles, y podrá jugar con la naturaleza como si fuera un gigantesco instrumento; y sin embargo, no comprenderá nada. ${ }^{\prime 5}$ En este párrafo, Novalis contrapone de una manera magistral la explicación científica de los fenómenos naturales y la comprensión de los valores y de las acciones humanas. La explicación científica transforma el mundo en algo incomprensible para el hombre, y desde este punto de vista, la hermenéutica analógica que desarrollan los autores de la obra de la analogía al símbolo, es un esfuerzo por extraer el significado oculto de las palabras y de los símbolos, en el límite entre la univocidad de los conceptos abstractos, que eliminan la parte de lo sensible, y la equivocidad del lenguaje sensible que nunca alcanza la plenitud y la unidad del espíritu. La hermenéutica parte

Lugar citado, Legros, R., Lidée d'humanité, Grasset, 1990, p. 91. 
de esta misma idea que expresan los románticos, Schleiermacher, Novalis etc., según la cual lo infinito se encuentra en lo finito, lo espiritual en el corazón de lo sensible, lo universal en lo particular. Y los autores del libro intentan reapropiarse de este espíritu romántico (sin caer en el subjetivismo radical) que destruye las pretensiones de la ilustración de universalizar y absolutizar los conceptos de la razón, con el fin de reivindicar el misterio que nos encadena a la vida y a sus símbolos. 